\title{
Application of the Queuing Analytic Theory in Emergency Department
}

\author{
Nabil Tachfouti ${ }^{1, *}$ \\ ${ }^{1}$ Laboratory of Epidemiology, Clinical Research and Community Health, Faculty of Medicine and Pharmacy, University Sidi Mohammed Ben Abdallah, Fez, Morocco \\ ${ }^{*}$ Corresponding author: Nabil Tachfouti, Laboratory of Epidemiology, Clinical Research and Community Health, Faculty of Medicine and Pharmacy, University Sidi Mohammed Ben \\ Abdallah, Fez, Morocco. Tel:+212-615293711, Fax: +212-535619120, E-mail: nabil.tachfouti@usmba.ac.m
}

Received: February 1, 2013; Accepted: February 12, 2013

Keywords: Emergency Department; Queuing Theory Analysis

\section{Dear Editor,}

I read with great interest the article by Alavi-Moghaddam et al. (1) in which the authors concluded that application of the queuing theory analysis can improve movement and reduce the waiting times of patients in bottlenecks within the emergency department (ED) in Iran. As an epidemiologist in Morocco, I divide the frustration of the authors that throughput of patients in the emergency department can often be hindered by several medical and organizational factors. In Morocco, unlike most countries, emergency departments do not provide care for patients with acute severe conditions alone. Inappropriate uses of ED and underutilization of regulation centers during triage represent a burden on health system and increase the demand for $\operatorname{ED}(2,3)$. I believe most emergency physicians in Morocco would presume that lack of such legal mandate concerning regulation use and appropriate consultation in ED would result in less crowd and difficulties in patient flow in emergency departments outside of Morocco.

As this article showed, work is also underway to address overcrowding in EDs and to improve patient flow. Timely access to an emergency provider is a critical dimension of quality for ED. Similar to Morocco, the Iranian emergency department analyzed in this article faces obstacles regarding personnel, lab processing and results, and critical care bed availability. We illustrate how data analysis using the queuing model, by providing a more rigorous and scientific basis for predicting patient delays to be vis- ited by a provider, is an appropriate simulation method to analyze the way to improve ED staffing and procedures. The usefulness of queuing models in guiding ED provider scheduling decisions was demonstrated elsewhere $(4,5)$. It would be interesting to study the impact of implementing solutions to the identified challenges for reducing emergency department waiting and patient holding times. Such added data would be of great interest to policy makers to maximize the effectiveness of ED and provide the best possible care to patients not only in Iranian emergency departments, but also in emergency departments worldwide.

\section{References}

1. Alavi-Moghaddam M, Forouzanfar R, Alamdari S, Shahrami A, Kariman H, Amini A, et al. Application of Queuing Analytic Theory to Decrease Waiting Times in Emergency Department: Does it Make Sense? Arch Trauma Res. 2012;1(3):101-7.

2. Tachfouti N, Bhatti JA, Nejjari C, Kanjaa N, Salmi LR. Emergency trauma care for severe injuries in a Moroccan region: conformance to French and World Health Organization standards. $J$ Healthc Qual. 2011;33(1):30-8.

3. Berraho M. Les consultations non appropriées aux services des urgences: étude dans un hôpital provincial au Maroc. Prat Organ Soins. 2012;43(3):197-204.

4. Green LV, Soares J, Giglio JF, Green RA. Using queueing theory to increase the effectiveness of emergency department provider staffing. Acad Emerg Med. 2006;13(1):61-8.

5. Green LV. Using Queueing Theory to Alleviate Emergency Department Overcrowding. Wiley Encyclopedia of Operations Research and Management Science; 2010. 